\title{
DEMOCRACIA, GESTÃO PARTICIPATIVA E TECNOCRACIA : UMA CRÍTICA À RAZÃO NEOLIBERAL
}

\author{
Diego Reis \\ Doutorando em Filosofia - PPGF/UFRJ \\ Bolsista CNPq
}

\begin{abstract}
RESUMO: A leitura de Foucault do neoliberalismo como racionalidade governamental, e não mera doutrina econômica ou ideológica, tem suscitado inúmeros debates atualmente. Trata-se, nesse artigo, de apresentar algumas consequências em relação a esta interpretação e pensar de que modo este cálculo governamental comporta novos deslocamentos e novas capturas biopolíticas no quadro geral das pesquisas do filósofo.
\end{abstract}

Palavras-chave: Democracia, Gestão participativa, Tecnocracia, Foucault

Pensar as figuras e os espectros da política contemporânea é tarefa premente de nosso tempo. Este exercício exige, necessariamente, uma redefinição de objetos e de perspectivas de análise no contexto das modificações da reflexão política nos últimos decênios. Sobretudo quando presenciamos, estarrecidos, à expansão das linhas regressivas que perpassam esse campo de discussão e das estratégias discursivas homogeneizantes a que suscitam. Refletir sobre os modos de operação da política hoje, portanto, é colocar em questão seus processos e procedimentos, tendo por horizonte que, se política significa conflito, "em toda a parte se está em luta", como diria Michel Foucault. 
AnaLógos, Rio de Janeiro, v. 1, 2016, p. 59-68

Em sua forma neoliberal, a democracia, cujas virtudes comumente são elencadas em contraposição aos perigos e desvios dos totalitarismos, se institui na contemporaneidade como único modelo legítimo de configuração governamental de sociedade. Enquanto governos ocidentais se preocupam em disseminá-la pelos quatro cantos do mundo, quer pela retórica oficial de chefes de governo e ministros ciosos de potenciais extensões de influência ou de mercados, quer pela força das armas e das "guerras humanitárias, justas e preventivas", a democracia liberal do ocidente e seus avatares, ligados à igualdade e à liberdade do indivíduo, se consolidam como modelo por excelência da governança política mundial. Modelo, com efeito, em consonância com os princípios de certo "individualismo democrático", por meio do qual a igualdade formal em face do aparelho jurídico-legal - em tese garantiriam as liberdades individuais e a equidade dos cidadãos.

O cenário pós-Guerra Fria, com a desconstrução da partilha simbólica que marcava os traços fronteiriços entre o mundo democrático ocidental e o mundo comunista de além-mar (alteridade política perante a qual a própria democracia se definia em sua especificidade, por oposição à efígie da foice e do martelo), embaralha as cartas do jogo e o consenso em torno do conceito e do fato da democracia. O triunfo do discurso democrático, todavia, e o novo consenso que se constituiria, desde então, em torno de um pacto internacional pela "democratização" do planeta, com suas organizações supranacionais e as prerrogativas de desenvolvimentismo, progresso econômico e efetivação dos "direitos humanos universais", implicou no estabelecimento de outro arranjo político planetário, acomodado à nova ordem mundial e à disposição geopolítica das potências hegemônicas e seus interesses.

Identificada ao consumo de massa, como sustenta Jacques Rancière em seu livro-manifesto O Ódio à Democracia [La Haine de la Démocratie], a ideia de uma democracia em construção e sempre por vir ${ }^{1}$, isto é, inacabada no

\footnotetext{
${ }^{1} \mathrm{O}$ filósofo franco-magrebino Jacques Derrida ao vincular desconstrução e democracia também partilha dessa ideia, segundo a qual é em nome da "democracia por vir" que a democracia deve ser questionada,
} 
AnaLógos, Rio de Janeiro, v. 1, 2016, p. 59-68 tempo presente, mas que se reconfigura continuamente em nome da democracia, é substituída pela incorporação de postulados técnicos e tecnocráticos no governamento racional da população e na representatividade como forma, por excelência, de exercício do poder político. Os "indivíduos democráticos" concebem esta forma de governo, desde então, como garantia da promoção e da salvaguarda de seus direitos e interesses individuais, limitando o escopo de ação do Estado, que deve se abster de intervir em domínios nos quais seus mecanismos se chocam a esferas da vida individual, recoberta pelos códigos jurídico-institucionais.

Ao reduzir os viventes humanos a conjuntos populacionais objetiváveis e ao fomentar um consenso democrático, o neoliberalismo toma de assalto a democracia liberal, convertendo-a em uma técnica de governamento econômico-gestionária, em virtude dos imperativos que faz funcionar e da capitalização das discussões em seus termos. Enquanto prática administrativa, a "redução da democracia a um estado de sociedade" ${ }^{2}$, como caracteriza Rancière, nos moldes do neoliberalismo, não deixou de avançar nos últimos decênios do século XX e XXI, mitigando os esforços de redefinição conceitual e a reinserção crítica da discussão na esfera pública, no concernente às suas instituições, princípios e aporias. Como remarca Wendy Brown:

A racionalidade neoliberal forma cada ser humano, cada instituição, incluindo o Estado constitucional, sob o modelo da empresa, e substitui os princípios democráticos por aqueles da conduta empresarial em toda a vida política e social. Após ter reduzido a migalhas a substância política da democracia, o neoliberalismo monopolizou o termo para servir a seus objetivos, com a consequência de que a "democracia de mercado", antiga expressão de escárnio, tornou-se a maneira ordinária de descrever uma forma que não tem mais nada a ver com o poder do povo. ${ }^{3}$

bem como suas instituições, princípios e conceitos-chave. Segundo o filósofo, esta é a promessa de revolução do político e do exercício da política em direção à sua gradativa perfectibilidade.

${ }^{2}$ RANCIÈRE, J. O Ódio à Democracia. p. 31.

3 BROWN, W. "Nous Sommes Tous Démocrates à Present". In: et al. Démocratie, dans quel état?. p.63. 
É problematizando igualmente o sentido ambiguo do conceito de AnaLógos, Rio de Janeiro, v. 1, 2016, p. 59-68
o sentido ambíguo do conceito de "democracia", por sua vez, que Agamben, no pequeno ensaio intitulado Nota introdutória sobre o conceito de democracia [Note liminaire sur le concept de démocratie], chama atenção para a dupla acepção do termo, fraturado semanticamente, podendo se referir tanto à forma de legitimação do poder quanto às modalidades de seu exercício:

O sistema político ocidental resulta da nodulação de dois elementos heterogêneos, que se legitimam e se dão consistência mutuamente: uma racionalidade político-jurídica e uma racionalidade econômico-governamental; uma "forma de constituição" e uma "forma de governo" [gouvernement] ${ }^{4}$.

Direito público de um lado; técnica de governo de outro. A democracia, em sua polissemia conflitiva, se metamorfoseia em um sistema de governança das instâncias políticas tradicionais de representação e mediação, convertendose, ela mesma, em mero mecanismo de representação. Não é de se estranhar, pois, que ao ser tomada primordialmente como técnica de governo, no modelo neoliberal, a democracia seja marcada pela tecnocracia que se prolifera em todos os seus âmbitos, ou seja, passa a ser "coisa de especialista", isto é, um saber (estranhamente) "privado" que move as engrenagens da governabilidade e dos acordos interpartidários.

A gestão "participativa" da máquina pública levada a cabo pela racionalidade neoliberal, por outro lado, faz do Estado "uma empresa a serviço das empresas" ${ }^{5}$. A Cultura de empresa e da adesão voluntária, embasada pelo discurso da cooperação e da free trade faith (a fé no livre comércio), cujos pilares são a eficácia, a eficiência e a maximização de efeitos com o menor dispêndio possível, despolitiza a relação dos cidadãos para com o Estado,

\footnotetext{
${ }^{4}$ AGAMBEN, G. “Note Liminaire sur le Concept de Démocratie". In: et al. Démocratie, Dans Quel État? p.9.

${ }^{5}$ DARDOT P. \& LAVAL, C. La Nouvelle Raison du Monde: Essai Sur la Société Néolibérale. p.370. 
AnaLógos, Rio de Janeiro, v. 1, 2016, p. 59-68 assentando em foros estritamente econômicos o que seria de ordem política e popular.

É no bojo dessa democracia "plural de individualidades" que temos visto, por exemplo, a escalada vertiginosa dos grupos de extrema-direita, que rejeitam, na pretensa defesa de uma coesão do Mesmo, alteridades vistas como perigosas à manutenção da ordem social e das identidades hegemônicas constituídas. Nesse sentido, corroída paulatinamente desde seu interior, a democracia em vez de significar um alargamento da possibilidade do exercício político sob os pilares da igualdade no Estado democrático de direito, se volta contra si mesma, pois, sob a acusação da "tirania das maiorias" e da crise da representatividade em curso, se reduz ao ritual eleitoral periódico: a "festa" da democracia - que evidencia, às avessas, a opacidade democrática dos processos participativos.

Nesta conjuntura, promover a integração é a ordem do dia, não obstante as dinâmicas de in/exclusão serem eficientes modos de normalização de grupos e práticas sociais. A lógica de expansão dos mercados consumidores pressupõe a intensificação do discurso democrático - diga-se de passagem, não crítica, mas uma espécie de bloco monolítico e unívoco do exercício político legítimo -, e, por isso, se torna importante estabelecer por espelhamento espaços supostamente democráticos, como o mercado, cujo qualificativo segue uma definição simplista e esvaziada de significação política efetiva. Para os neoliberais, "a democracia deve somente criar condições viáveis para que o mercado funcione bem e segundo suas próprias regras" ${ }^{\prime 6}$. E, na medida em que - mercado passa a realizar a paridade entre os indivíduos, "iguais" na possibilidade de adquirir seus produtos e realizar trocas comerciais, é o Estado que se torna um apêndice do mercado, ou instância que deve dar as garantias de que o "jogo" transcorrerá sem interrupções, de maneira ordenada em todas as suas regras procedimentais.

\footnotetext{
${ }^{6}$ CANDIOTTO, C. Neoliberalismo e Democracia. p.164.
} 
AnaLógos, Rio de Janeiro, v. 1, 2016, p. 59-68

A democracia deixa de ser considerada em sua acepção como modo de

vida e de garantia do exercício da cidadania. Doravante, a democracia mínima ou limitada, tal como defendida por Hayek ${ }^{7}$, ganha a função de mediadora do ambiente das trocas e de constituição de uma cidadania administrada no campo da autonomia e das liberdades de mercado.

A corrida pela inclusão no mercado da cidadania tem como contraponto a produção e a naturalização de uma série de identidades, cujos efeitos de poder são reguladores da própria inserção democrática ou, ao contrário, dos limites e penas imputados pelo instrumental jurídico-legal. O "bom cidadão" que se pretende forjar, trabalhador e que gere com competência a sua empresa-vida, credenciais requeridas para inclusão na realidade homogênea da comunidade assegurada, evidencia, sem dúvida, o uso a que está submetido o discurso das democracias avançadas para subjugação das alteridades ameaçadoras. Isto é, a cidadania neoliberal não é desarticulada da produção de subjetivação, cujo avatar é, por excelência, o homo oeconomicus empresário de si.

Não será supérfluo notar que,

afirmar que não existe democracia sem mercado não supõe, reciprocamente, afirmar a impossibilidade do mercado sem a consequente existência da democracia. A 'verdadeira' democracia precisa do mercado; embora o mercado não precise inevitavelmente dela. (GENTILLI apud CANDIOTTO, 2010, p. 165)

Não obstante, a expansão dos mercados e a incorporação dos direitos humanos e sociais inaugura um período de mundialização do exercício da política, que tende a fazer da democracia liberal o discurso da única ordem legítima. Em contrapartida, analogamente, há a ampliação sem precedentes na história ocidental das sociedades de controle, assim conceituadas por Deleuze a partir de seu diálogo com Foucault, vetores de circulação dos racismos de toda

\footnotetext{
${ }^{7}$ Cf. HAYEK, F. A. O Caminho da Servidão. Rio de Janeiro: Expressão e Cultura: Instituto Liberal, 1987.
} 
AnaLógos, Rio de Janeiro, v. 1, 2016, p. 59-68 espécie, que cindem na prática e simbolicamente o mundo entre "nós" e os "Outros", ou ainda, em distinção amigo/inimigo global.

Notórios, nesse sentido, a título de exemplo, são dois discursos que embasam práticas políticas que se tangenciam em muitos aspectos. Primeiro, a invocação do neoliberalismo, em 1980, no governo norteamericano de Reagan e as cruzadas contra o "império do mal", materializado na figura dos comunismos. Depois, a famigerada "Doutrina Bush", sintetizada nas "Estratégias de Segurança Nacional dos Estados Unidos", de 2002, um dos bastiões do discurso democrático liberal e das "guerras contra o terror" do século XXI.

Ao estabelecer as bases da "democracia efetiva", tornando indissociáveis as liberdades econômicas e políticas, o dogmatismo de mercado toma as rédeas de condução das políticas e intervenções globais, liderados pelos norte-americanos e seu poderio bélico, econômico e político, legitimamente advindo de seu papel nas "grandes lutas do século vinte entre a liberdade e o totalitarismo [que] terminaram com a decisiva vitória das forças da liberdade - e de um único modelo sustentável para o sucesso das nações: liberdade, democracia e livre mercado". ${ }^{8}$

Estranho paradoxo, não se pode deixar de notar, quando em nome da "dignidade humana" e dos excessos do poder cometidos alhures, a força e a truculência exportadas passam a ser as armas que servem como instrumentos de controle e regulação para que se reestabeleçam os princípios de agência humana. Em nome da vida, da restruturação da ordem e dos valores democráticos será preciso intervir nos países "em risco", justificando - como outrora o discurso teológico-salvacionista legitimou colonialismos, genocídios e explorações - pela (suposta) defesa dos "direitos humanos", as ações bélicas mais truculentas.

Os interesses geopolíticos e geoestratégicos, evidentemente, são subjacentes aos pretensos ideais humanitários que assumem o discurso da vida

\footnotetext{
${ }^{8}$ National Security Strategy of the United States, 2002, p. 3.
} 
AnaLógos, Rio de Janeiro, v. 1, 2016, p. 59-68 e da liberdade para justificar, inclusive, exterminações de populações inteiras, sem contar na imposição global do modelo ocidental, logocêntrico e liberal, tido como o referencial político por excelência. No interior das contradições dos programas políticos de abrangência planetária, em nome da necessidade de viver, "os massacres tornaram-se vitais" 9 , como diagnostica Foucault no curso de 1976, Em Defesa da Sociedade, com a nuance, hoje, de serem considerados "massacres administrativos"

É, ainda, Agamben, em seu Estado de Exceção ${ }^{11}$, quem desenvolve análises mais pormenorizadas em relação à articulação do funcionamento dos Estados democráticos com a adoção de mecanismos extrajurídicos como regra das democracias contemporâneas. Democracias que vivem, permanentemente, sob o "paradigma da segurança como técnica normal de governo" ${ }^{12}$. $O$ próprio Estado, desta feita, se transforma potencialmente em objeto de intervenção, com vistas à manutenção da paz interior e ao combate do "inimigo interno", isto é, todos aqueles que poderiam colocar em xeque a ordem e os valores hegemônicos.

Não é de estranhar, nesse sentido, que os estados de exceção, apoiados nesta prerrogativa, sejam dispositivos contemplados pelas cartas constitucionais da maior parte das nações ao redor do globo, como mecanismo de salvaguarda e manifestação de sua própria razão. Estado e crime de Estado, desse modo, "coabitam na paradoxal interface entre legalidade e violência" ${ }^{13}$, modulada nas intervenções de saneamento pontuais ou nas medidas generalistas de conjunto, de caráter legal ou extralegal.

E isto sem que haja choque algum, portanto, entre esta prerrogativa e a razão neoliberal, que tipifica a democracia como extensão do mercado e garantia jurídica para que se estabeleçam espaços de livre competição entre setores público e privado. A democracia passa desempenhar uma função

\footnotetext{
${ }^{9}$ FOUCAULT, M. Em Defesa da Sociedade, p. 149.

${ }^{10}$ A expressão é de Hannah Arendt em seu Eichmann em Jerusalém.

${ }^{11}$ Cf. AGAMBEN, G. Estado de Exceção. Trad. Iraci Poleti. São Paulo: Boitempo, 2004.

12 Ibdem, p. 27-28.

${ }^{13}$ CASTELO BRANCO, 2013, p.150.
} 
AnaLógos, Rio de Janeiro, v. 1, 2016, p. 59-68 meramente protetiva entre os diferentes atores políticos no mercado livre, dando garantias aos parceiros no que diz respeito ao funcionamento (desregulado) do jogo.

A democracia, entretanto, como possibilidade de uma vida política não é um e/Estado acabado, mas em permanente e tensionado alargamento, irredutível às técnicas de governo, ou a determinadas instituições que lhe dão suporte. Reinventar a democracia, nesse sentido, para além dos marcos estabelecidos pela racionalidade neoliberal torna-se fundamental para que se redefina nas bases do comum a sua força disruptiva, ou mesmo escandalosa, como propõe Rancière ${ }^{14}$, ainda que para isso seja preciso "invadir" ou reconquistar os espaços açambarcados pelo mercado.

\section{BIBLIOGRAFIA}

AGAMBEN, G. "Note Liminaire sur le Concept de Démocratie". In: et al.

Démocratie, dans quel état? Paris: La Fabrique Éditions, 2009.

BROWN, W. "Nous Sommes Tous Démocrates à Present". In: et al.

Démocratie, dans quel état? Paris: La Fabrique Éditions, 2009.

CANDIOTTO, C. Neoliberalismo e Democracia. Revista Princípios. Natal (RN), v.19, n.32, Jul/Dez. 2012.

CASTELO BRANCO, G. Estado e Crime: extermínio, intimidação, exclusão. $\ln :$ . (org.) Terrorismo de Estado. Belo Horizonte: Autêntica Editora, 2013.

DARDOT P. \& LAVAL, C. La Nouvelle Raison du Monde: Essai Sur la Société Néolibérale. Paris: Éditions La Découverte, 2009.

\footnotetext{
${ }^{14}$ Cf. RANCIÈRE, op. cit.
} 
AnaLógos, Rio de Janeiro, v. 1, 2016, p. 59-68 FOUCAULT, M. Em Defesa da Sociedade. Curso no Collège de France, 1975 1976. Trad. Maria Ermantina Galvão. São Paulo: Martins Fontes, 2005.

Nascimento da Biopolítica. Trad. Eduardo Brandão. São Paulo: Martins Fontes, 2008.

NATIONAL SECURITY STRATEGY OF THE UNITED STATES 2002. Washington: The White House, 2002.

RANCIÈRE, J. O Ódio à Democracia. Trad. Mariana Echalar. São Paulo: Boitempo Editorial, 2014. 